\title{
Traditional smoking and e-smoking among medical students and students-athletes - popularity and motivation
}

\author{
ANDREI SHPAKOU ${ }^{1, A-E, ~ G}$, VALERIY KOVALEVSKIY², A, B, F, G, LUDMILA KLIMATSKAIA ${ }^{3, A-C, E-G}$,

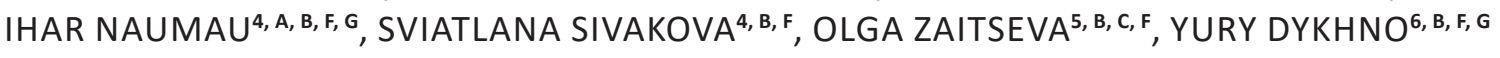 \\ ${ }^{1}$ Department of Sports Medicine and Rehabilitation, Yanka Kupala State University of Grodno, Belarus \\ ${ }^{2}$ Department of Childhood Psychology, Krasnoyarsk Pedagogical University named after V.P. Astafiev, Russia \\ ${ }^{3}$ Department of Social Pedagogy and Social Work, Krasnoyarsk State Pedagogical University, Russia \\ ${ }^{4}$ Department of General Hygiene and Ecology, Grodno State Medical University, Belarus \\ ${ }^{5}$ Science-Research Institute of Medical Problems of the North, Russian Academy of Sciences, Siberian Branch, \\ Krasnoyarsk, Russia \\ ${ }^{6}$ Department of Oncology and Radiation Therapy of Krasnoyarsk State Medical University, Russia
}

A - Study Design, B - Data Collection, C - Statistical Analysis, D - Data Interpretation, E - Manuscript Preparation, F - Literature Search, G - Funds Collection

Summary Background. Of particular interest is a study of the consumption rates of some psychoactive drugs in a specific group of medical students and students-athletes, who are advocates of a healthy lifestyle according to their occupation.

Objectives. The purpose of this paper was the evaluation of the prevalence of tobacco smoking and e-cigarette smoking (vaping) among medical students and students-athletes and the research of students' motivation and attitudes towards smoking in its various forms.

Material and methods. 1,725 medical students and students-athletes were surveyed. All the respondents were divided into 4 groups: exclusive tobacco smokers, exclusive e-cigarette smokers, dual smokers (both e-cigarette and tobacco cigarette users), non-smoking students who hadn't smoked for at least 12 months.

Results. 1,515 of the surveyed students $(87.8 \%)$ declared themselves as non-smokers, $160(9.3 \%)$ respondents smoked traditional cigarettes. E-cigarettes were used much less often than traditional cigarettes -50 respondents $(2.8 \%)$. One-time tobacco smoking was recorded in the medical history of 992 (57.5\%) of students; e-smoking - 780 (45.2\%). Statistically, men appeared to have been twice as common as women among both tobacco and e-cigarette smokers. Dual smokers used traditional cigarettes less often than electronic cigarettes. This group more often chose e-liquid with a higher level of nicotine. An attempt to stop smoking was the most important stimulus of opting for vaping $(90.5 \%)$.

Conclusions. Among the students of both groups, vaping is not frequent and not a popular practice compared to traditional tobacco smoking. Everyday smokers prevailed among dual smokers and not among exclusive e-cigarette smokers. E-smokers, more often than other respondents, believe that vaping is safe for their health and the health of others.

Key words: electronic nicotine delivery systems, smoking, tobacco products, medical students, students-athletes.

Shpakou A, Kovalevskiy V, Klimatskaia L, Naumau I, Sivakova S, Zaitseva O, Dykhno Y. Traditional smoking and e-smoking among medical students and students-athletes - popularity and motivation. Fam Med Prim Care Rev 2018; 20(1): 61-66, doi: https://doi.org/10.5114/ fmpcr.2018.73705.

\section{Background}

Electronic smoking (electronic system of nicotine delivery, e-cigarette) is often branded as an effective alternative to tobacco smoking in mass media [1]. The influence of e-cigarettes on the human organism is being discussed endlessly as 'substitutes' for traditional cigarettes are growing in popularity among their consumers. The scientific research carried out in recent years $[2,3]$ does not prove the efficacy promoted in popular sources of e-cigarettes as an effective method enabling reduction or the giving up of tobacco smoking. The investigation could have demonstrated a well-grounded opinion on the influence of e-cigarettes on human health and the environment [4-6]. This can be explained by the recent popularity of e-smoking, which does not exceed 15 years. The first inventor of the e-cigarette prototype was Herbert A. Gilbert, who patented 'a smokeless tobacco-free cigarette' back in 1965 . Modern electronic cigarettes were invented in 2003 by the Chinese pharmacist Hon
Lik, and in 2004, Ruyan Group Ltd. patented their working principle and manufacturing technology. Instead of tobacco, an e-cigarette contains a cartridge with liquid consisting of glycerin and/or propylene glycol, flavoring substances, as well as nicotine of different concentrations. The liquid vaporizes under the influence of a heating unit (atomizer) and an ultrasound sprinkler, causing the formation of vapor resembling tobacco smoke, but which is flavorless. Current well-established terms of e-cigarettes are vaporizing or vaping [1].

Although the popularity of electronic smoking differs among European countries [7], it is common to hear about the growing popularity of vaping as such and of the emergence of a new concern for public healthcare and health (the effect on the organism of substances constituting e-liquid, including nicotine; the use of an e-cigarette as a source of cannabinoids and other prohibited drugs) [8-10]. Due to the short time of availability of electronic cigarettes, knowledge about their possible impact on human health is obscure [1]. The World Health Organization recommends taking measures for limiting the trade of electron- 
ic cigarettes to minors, banning advertising campaigns in mass media and smoking in public places, equating the danger coming from e-cigarettes with the threat of traditional smoking [9].

There is no data supporting this type of research among students between 18 and 26 years old in Belarus, who are arguably the main consumers of e-cigarettes. The development and implementation of a range of preventive measures aiming at maintenance and reinforcement of public health require a study on the main characteristic and principles of lifestyles related to different social groups. Particular interest lies in the usage of some psychoactive drugs. Medical students and students-athletes, who are to become the advocates of correct life principles, health values and merits of a healthy lifestyle, are a good target group. This work covers survey results collected from medical students (Faculty of General Medicine of Medical University and students-athletes Faculty of Physical Culture of Pedagogical University) who represent the professions which are to exemplify a healthy lifestyle in the future. Unfortunately, the findings in the investigation reveal that consumption of psychoactive drugs, including nicotine, is quite frequently consumed in this target group [11-13].

\section{Objectives}

The purpose of this paper is to evaluate the incidence of tobacco and e-cigarette smoking (vaping) among medical students and students-athletes and to examine the students' motivation and attitudes towards different types of smoking.

\section{Material and methods}

\section{Study location and respondents}

The research was carried out from March 2017 to November 2017 in Grodno (Belarus). The analysis of the responses of 1,725 medical students and students-athletes ( $n=1,223$ from medical university and $n=502$ from pedagogical university) made it possible to distinguish 4 groups of respondents: exclusive tobacco smokers, e-cigarettes smokers, dual smokers (smoking both electronic and traditional cigarettes), non-smokers and non-smoking students (at least 12 months before filling in the survey). The general characteristics of our study participants are provided in Table 1 . The data is presented as median values with a min.-max. range.

The age of the respondents was presented as median values with minimal and maximal ranges due to non-parametric distribution of variables. The median age was 19 years (IQR = 18-20) (for medical students IQR $=18-20$, for students-athletes $I Q R=18-21)$ without differences between males $(I Q R=18-21$ years) and females (IQR $=18-20$ years), accordingly. The female respondents outnumbered the male respondents $(68.3 \%$ versus $31.7 \%$, respectively), which reflects the students' gender balance at the faculties in each university and guarantees consistency between the group of respondents and the population of students studying at these universities.

\section{Data collection instruments and operational definitions}

The investigation was completed as part of the international scientific project 'YoUng People E-Smoking Study' (YUPESS) [14]. Completion of the database was achieved through voluntary conduct of an anonymous electronic survey in the Limesurvey [15] web-application, which allowed for a considerable decrease in the expenses allotted to the investigation and for streamlining the collection and interpretation of the data. The survey, offered by researchers from the Silesian Medical University in Katowice (Poland) [14], included 35 questions targeting the prevalence and attitudes of youth towards tobacco smoking and vaping. The survey's authors permitted its translation into Russian for further use, which included the back translation technique. The questions in the survey addressed the problems of safety (influence on the smoker's health and the health of others), the level of awareness of possible addiction and motives for use. The percentage of the surveyed exceeded $85 \%$ and $90 \%$ of the entire number of students at the selected faculties.

This investigation was examined and approved of by the Ethics Committee of Yanka Kupala State University of Grodno (no. 10-03-2017 N3).

\section{Statistical analysis}

Statistical analysis was performed using the statistical software STATISTICA 10, StatSoft. Variables with non-normal distribution were presented as median, minimal and maximal values (distributions of the variables were tested with the Shapiro-Wilk test). Nominal data is presented as percentages. The distribution of the categorical variables was shown by frequencies and proportions, along with $95 \%$ confidence intervals. Statistical comparisons were completed using independent samples chi-squared analysis. The non-parametrical Mann-Whitney $U$ test for medians was used for comparison of the differences between groups. Significant differences were defined as a $p$-value of less than 0.05 .

\section{Results}

\section{Prevalence of traditional tobacco smoking compared to the use of e-cigarettes}

Most of the surveyed students (87.8\%) and approximately an equal number of medical students and students-athletes declared a non-smoking status at the moment of questioning or confirmed to have been non-smoking for the previous 12 months. 160 students $(9.3 \%$ of the entire number of respondents) smoked tobacco, whereas electronic cigarettes were used much less often -50 (2.9\%), (36 dual smokers stated they were using both tobacco cigarettes and e-cigarettes, 14 respondents consumed e-cigarettes only). The smokers differed with regard to gender $(p<0.05)$, and the frequency of smoking both types of cigarettes was greater in males (Table 2). Male dual smokers amounted to $6.6 \%$, while female dual smokers $-2.0 \%$ $(p<0.01)$.

\begin{tabular}{|l|l|l|l|l|l|l|}
\hline \multirow{2}{*}{ Table 1. Characteristics of the study participants } & \multicolumn{2}{l|}{ Students-athletes } & \multicolumn{2}{l|}{ All } \\
\hline \multirow{2}{*}{ Variables } & Medical students & Female & Male & Female & Male & Female \\
\cline { 2 - 7 } & Male & 942 & 266 & 236 & 547 & 1,178 \\
\hline Number of participants & 281 & {$[19]$} & {$[20]$} & {$[20]$} & {$[19]$} & {$[19]$} \\
$\begin{array}{l}\text { Age [median] } \\
\text { (min.-max., IQR) }\end{array}$ & $\begin{array}{l}{[19]} \\
(18-26,18-20)\end{array}$ & $(18-26,18-20)$ & $(18-21,18-21)$ & $(18-23,18-22)$ & $(18-26,18-21)$ & $(18-26,18-20)$ \\
\hline
\end{tabular}




\begin{tabular}{|c|c|c|c|c|c|c|c|}
\hline \multirow[t]{2}{*}{$\begin{array}{l}\text { Groups of re- } \\
\text { spondents }\end{array}$} & \multicolumn{3}{|c|}{$\begin{array}{l}\text { Male }[\%](95 \% \mathrm{Cl})^{*} \\
n=547\end{array}$} & \multicolumn{3}{|c|}{$\begin{array}{l}\text { Female }[\%](95 \% \mathrm{Cl}) \\
n=1,178\end{array}$} & \multirow{2}{*}{$\begin{array}{l}\text { All [\%] } \\
(95 \% \text { CI }) \\
n=1725\end{array}$} \\
\hline & $\begin{array}{l}\text { Medical } \\
\text { students } \\
n=281 \\
\end{array}$ & $\begin{array}{l}\text { Students- } \\
\text {-athletes } \\
n=266\end{array}$ & Total & $\begin{array}{l}\text { Medical } \\
\text { students } \\
n=942 \\
\end{array}$ & $\begin{array}{l}\text { Students- } \\
\text {-athletes } \\
n=236\end{array}$ & Total & \\
\hline Tobacco smoking & $\begin{array}{l}58[20.6] \\
(15.9-25.4)\end{array}$ & $\begin{array}{l}20[7.5]^{*} \\
(4.4-10.7)\end{array}$ & $\begin{array}{l}78[14.3] \\
(11.3-17.2)\end{array}$ & $\begin{array}{l}59[6.3] \\
(4.7-7.8)\end{array}$ & $\begin{array}{l}23[9.8]^{*} \\
(6.0-13.5)\end{array}$ & $\begin{array}{l}82[7.0]^{*} \\
(5.5-8.4)\end{array}$ & $\begin{array}{l}160[9.3] \\
(7.9-10.7)\end{array}$ \\
\hline Vaping & $\begin{array}{l}8[2.9] \\
(0.9-4.8)\end{array}$ & $\begin{array}{l}3[1.1] \\
(-0.14-2.4)\end{array}$ & $\begin{array}{l}11[2.0] \\
(0.8-3.2)\end{array}$ & $\begin{array}{l}1[0.1] \\
(-0.1-0.3)\end{array}$ & $\begin{array}{l}2[0.9] \\
(-0.3-2.0)\end{array}$ & $\begin{array}{l}3[0.3]^{*} \\
(-0.04-0.5)\end{array}$ & $\begin{array}{l}14[0.8] \\
(0.4-1.2)\end{array}$ \\
\hline $\begin{array}{l}\text { Tobacco smoking } \\
\text { + vaping }\end{array}$ & $\begin{array}{l}22[7.8] \\
(4.7-11.0)\end{array}$ & $\begin{array}{l}3[1.1]^{*} \\
(-0.14-2.4)\end{array}$ & $\begin{array}{l}25[4.6] \\
(2.8-6.3)\end{array}$ & $\begin{array}{l}10[1.1] \\
(0.4-1.7)\end{array}$ & $\begin{array}{l}1[0.4] \\
(-0.4-1.25)\end{array}$ & $\begin{array}{l}11[0.9]^{*} \\
(0.4-1.5)\end{array}$ & $\begin{array}{l}36[2.1] \\
(1.4-2.8)\end{array}$ \\
\hline Non-smokers & $\begin{array}{l}193[68.7] \\
(63.3-74.1)\end{array}$ & $\begin{array}{l}240 *[90.2] \\
(86.7-93.8)\end{array}$ & $\begin{array}{l}433[79.2] \\
(75.7-82.6)\end{array}$ & $\begin{array}{l}872[92.6] \\
(90.9-94.2)\end{array}$ & $\begin{array}{l}210[89.0]^{*} \\
(85.0-93.0)\end{array}$ & $\begin{array}{l}1,082[91.9]^{*} \\
(90.1-93.4)\end{array}$ & $\begin{array}{l}1,515[87.8] \\
(86.3-89.4)\end{array}$ \\
\hline
\end{tabular}

$* p$ - a two-tailed probability value of the $\chi^{2}$ test for comparison of medical students and students-athletes $(p<0.05)$.

\begin{tabular}{|c|c|c|c|c|c|c|c|}
\hline \multirow[t]{2}{*}{ Groups of respondents } & \multicolumn{3}{|c|}{ Male [\%] $(95 \% \mathrm{CI})^{*}$} & \multicolumn{3}{|c|}{ Female [\%] $(95 \% \mathrm{Cl})^{*}$} & \multirow{2}{*}{$\begin{array}{l}\text { All [\%] } \\
(95 \% \mathrm{Cl})\end{array}$} \\
\hline & $\begin{array}{l}\text { Medical } \\
\text { students }\end{array}$ & $\begin{array}{l}\text { Students- } \\
\text {-athletes }\end{array}$ & Total & $\begin{array}{l}\text { Medical } \\
\text { students }\end{array}$ & $\begin{array}{l}\text { Students- } \\
\text {-athletes }\end{array}$ & Total & \\
\hline $\begin{array}{l}\text { Non-smokers tobacco at } \\
\text { the time of the survey }\end{array}$ & $\begin{array}{l}182[64.8] \\
(59.2-70.4) \\
\end{array}$ & $\begin{array}{l}165[62.0] \\
(56.2-67.9) \\
\end{array}$ & $\begin{array}{l}347[63.4] \\
(59.4-67.5)\end{array}$ & $\begin{array}{l}496[52.7] \\
(49.5-55.8)\end{array}$ & $\begin{array}{l}149[63.1]^{* *} \\
(57.0-69.3) \\
\end{array}$ & \begin{tabular}{|l}
$645[54.8]^{* *}$ \\
$(51.9-57.6)$ \\
\end{tabular} & $\begin{array}{l}992[57.5] \\
(55.2-59.8) \\
\end{array}$ \\
\hline $\begin{array}{l}\text { The age of the first } \\
\text { attempt at tobacco } \\
\text { smoking* }\end{array}$ & $15(10-21)$ & $15(10-21)$ & $15(10-21)$ & $16(10-23)$ & $16(10-21)$ & $16(10-23)$ & $16(10-23)$ \\
\hline $\begin{array}{l}\text { Non-smokers e-cigarette } \\
\text { at the time of the survey }\end{array}$ & $\begin{array}{l}172[61.2] \\
(55.5-66.9)\end{array}$ & $\begin{array}{l}134[50.4]^{* *} \\
(44.4-56.4)\end{array}$ & $\begin{array}{l}306[55.9] \\
(51.8-60.1)\end{array}$ & $\begin{array}{l}371[39.4] \\
(36.3-42.5)\end{array}$ & $\begin{array}{l}103[43.6] \\
(37.3-50.0)\end{array}$ & $\begin{array}{l}474[40.2]^{* *} \\
(37.4-43.0)\end{array}$ & $\begin{array}{l}780[45.2] \\
(42.9-47.6)\end{array}$ \\
\hline $\begin{array}{l}\text { The age of the first } \\
\text { attempt at e-cigarette } \\
\text { smoking* }\end{array}$ & $17(11-23)$ & $17(13-23)$ & $17(11-23)$ & $17(12-23)$ & $18(12-23)$ & $17(12-23)$ & $17(11-23)$ \\
\hline
\end{tabular}

* Data of the age of the first attempt at tobacco smoking and e-cigarette smoking presented as median values with min.-max. range; ** a two-tailed probability value of the $\chi^{2}$ test for comparison of medical students and students-athletes $(p<0.05)$.

\section{Status of tobacco smoking and vaping among students}

At the time when the survey was being carried out, medical student smokers outnumbered smoking students-athletes two to one. The same statistical difference lies in the number of dual smokers among medical students and students-athletes. Female students-athletes, however, smoked traditional cigarettes more often than their peers from the medical school, and they smoked traditional cigarettes more frequently than their medical school counterparts, which the student indicated in their medical history. In total, 1,107 (64.2\% of respondents) denoted trying smoking attempt in their life. Among non-smokers, at the time of the survey, over 897 (59.2\% of the respondents) had attempted smoking both tobacco and (or) electronic cigarettes. The average age of the first attempt at smoking was approx. 16 years of age (14-17), whereas the first experience of electronic smoking was 1 years older - 17 (12-23). Nearly every time, a traditional cigarette was the first to have been smoked $(88.7 \%)$. The age of the first attempt at electronic smoking was clearly older among female students-athletes compared to the experience of their medical school peers. The attempt at smoking and the age of initiation, related to the respondents' group, is presented in Table 3.

The differences with regard to the quantity and frequency of traditional and e-cigarette consumption among the representatives of both groups of students have not been discovered. The length of a vaping habit appeared to be shorter than that of traditional smoking (12 months - min.-max. range 6-24 vs 24 months - min.-max. range 12-40) $(p<0.05)$. The length of the vaping habit of dual smokers was even shorter (12 - min.- -max. range 7-21 months), even though preceding and ongoing tobacco smoking had lasted over 18 months (min.-max. range 12-48 months). Everyday tobacco smoking was declared by $81.8 \%$ of smokers. The frequency of smoking appeared to be 8 (min.-max. range 5-10) cigarettes per day. Everyday vaping was confirmed by $47.4 \%$ of e-cigarette consumers. Dual smokers preferred everyday smoking (52.6\%) and more often smoked traditional cigarettes instead of electronic cigarettes (7.5 (min.-max. range) 3-10 vs 2 (min.-max. range 1-3) everyday $-p<0.05)$. Exclusive e-cigarette consumers smoked electronic cigarettes every day in $64.35 \%$ of cases; however, the number of cigarettes smoked was considerably smaller - 4 (min.-max. range $2-10)(p<0.05)$. Compared to tobacco smoking, e-cigarette use was not associated with a greater everyday intensity, especially among non-dual smokers (Table 4).

Traditional smokers and e-cigarettes consumers more often had at least one year of experience smoking. Two-thirds of dual smokers had experience smoking tobacco for over 1 year, while their experience of e-smoking did not exceed a length of 1 year. This brings us to the conclusion that traditional smokers replaced tobacco with e-cigarettes, but, affected by the long experience and high frequency of smoking as such, they were not able to utterly give up traditional smoking.

As far as e-liquid is concerned, the most popular purchase points appeared to be specialist stores (90\%) and/or shops and specialist departments in supermarkets (74.3\%). The choice of a particular cartridge depended on the level of nicotine (91.3\%) and/or the price (61.9\%). E-cigarette smokers barely used e-liquid with 'popular' levels of nicotine, those ranging from 8 to $16 \mathrm{mg} / \mathrm{ml}$ and higher. All the respondents used an e-liquid with a nicotine level below $8 \mathrm{mg} / \mathrm{ml}$. The analysis aimed at comparing tobacco smokers and dual smokers revealed that dual smok- 


\begin{tabular}{|c|c|c|c|c|}
\hline \multirow[t]{3}{*}{ Index } & \multicolumn{4}{|c|}{ Respondents-smokers [\%] $(95 \% \mathrm{CI}) * n=210$} \\
\hline & \multirow{2}{*}{$\begin{array}{l}\text { Exclusively tobacco } \\
n=160\end{array}$} & \multirow{2}{*}{$\begin{array}{l}\text { Exclusively e-cigarettes } \\
n=14\end{array}$} & \multicolumn{2}{|l|}{ Dual smokers $n=36$} \\
\hline & & & Traditional cigarettes & e-cigarettes \\
\hline \multicolumn{5}{|l|}{ Length of smoking } \\
\hline Under 6 months & $14[8.8](4.4-13.1)$ & $2[14.3](-4.0-32.6)$ & $2[5.6](-1.9-13.1)$ & $8[22.2](8.6-35.8)$ \\
\hline 6-12 months & $44[27.5](20.6-34.4)$ & 6 [42.9] (16.9-68.8) & $12[33.3](17.9-48.7)$ & 15 [41.7] (25.6-57.8) \\
\hline Over 12 months & $102[63.8](56.3-71.2)$ & $6[42.9]^{* *}(16.9-68.8)$ & $22[61.1](45.2-77.0)$ & $13[36.1](20.4-51.8)$ \\
\hline \multicolumn{5}{|l|}{ Frequency of smoking or vaping } \\
\hline Every day & $121[75.6](69.0-82.3)$ & $9[64.3]^{* *}(39.2-89.4)$ & $27[75.0](60.9-89.2)$ & $10[27.8](13.2-42.4)$ \\
\hline $2-3$ times a week & $8[5.0](1.6-8.4)$ & $3[21.4]^{* *}(0-42.9)$ & $2[5.6](-1.9-13.1)$ & 9 [25.0] (10.9-39.2) \\
\hline Once a week or less frequently & 21 [13.1] (7.9-18.4) & $2[14.3](-4.0-32.6)$ & $6[16.7](4.5)$ & 8 [22.2] (8.6-35.8) \\
\hline Less than once a week & $10[6.3](2.5-10.0)$ & 0 & $1[2.8](-2.6-8.2)$ & 9 [25.0] (10.9-39.2) \\
\hline \multicolumn{5}{|c|}{ Number of cigarettes smoked per day } \\
\hline $1-5$ & $54[33.8](26.4-41.1)$ & $10[71.4]^{* *}(47.8-95.1)$ & 14 [38.9] (23.0-54.8) & 32 [88.9] (78.6-99.2) \\
\hline $6-9$ & 49 [30.6] (23.5-37.8) & 0 & 9 [25.0] (10.9-39.2) & 0 \\
\hline 10 or over 10 & 57 [35.6] (28.2-43.1) & 4 [28.6] (4.9-52.2) & 13 [36.1] (20.4-51.8) & $4[11.1](0.8-21.4)$ \\
\hline
\end{tabular}

* - 95\% dependable interval; ** - a two-tailed probability value of the $\chi^{2}$ test for comparison of the groups of traditional smokers and e-smokers $(p<0.05)$.

\begin{tabular}{|l|l|l|l|l|}
\hline Table 5. Students' opinion on vaping & Non-smokers $n=1,515$ \\
\hline \multicolumn{7}{|l|}{ Respondents-smokers [\%] (95\% Cl) } & Vaping $n=14$ & $17[47.2](30.9-63.5)$ & $111[7.3](6.0-8.6)$ \\
\cline { 2 - 5 } & Tobacco $n=160$ & $6[42.9](16.9-68.8)$ & 19 [52.8] (36.5-69.1) & 737 [48.7] (46.1-51.2) \\
\hline E-cigarettes are health safe & $24[15.0](9.5-20.5)$ & $7[50.0](23.8-76.2)$ & $13[36.1](20.4-51.8)$ & $1077[71.1](68.8-73.4)$ \\
\hline Agree
\end{tabular}

ers more often resorted to e-liquid with high nicotine levels. As far as the levels of nicotine in e-liquid are concerned, there was no difference between medical students and students-athletes.

\section{Motivation for e-smoking}

There was no difference between the two groups of respondents with regard to the motivation for and preferences in vaping. Attempting to quit smoking tobacco proved to be the most frequent factor triggering the use of vaping (90.5\%), far more than the certainty of the less harmful effect on e-smokers' health (59.5\%) and on health of others (47.6\%). The financial burden was not the main factor for a switch to e-vaping. Only $23.1 \%$ of e-smokers promote vaping among their peers as an effective method for quitting smoking tobacco, $7.7 \%$ just recommend vaping, whereas more than two-thirds of e-smokers (38.5\%) did not recommend vaping at all; nonetheless, the same number of respondents are/have been active e-smokers.

\section{Opinion on smoking in public places}

Only $9.2 \%$ of all the respondents declared that e-smoking is harmless with regard to health $(10.4 \%$ of medical students and $6.2 \%$ of students-athletes). In general, the confidence in the harmless nature of e-cigarettes was shared by $11.5 \%$ of e-smokers ( $15 \%$ of tobacco smokers and $46 \%$ of e-smokers). Only $7.3 \%$ of non-smokers consider vaping safe for the health $(p<0.05)$. Approximately one-fifth of all the respondents did not state a clear opinion on the subject matter. Furthermore, when answering the question about the health safety of vaping, $46 \%$ of e-smokers considered it entirely harmless, whereas $54 \%$ of the respondents thought that vaping was dangerous, but not as risky as tobacco smoking. $67.2 \%$ of all the respondents supported a vaping ban in public places. This ban was favored by $32 \%$ of e-smokers, $41.3 \%$ of tobacco smokers and $71 \%$ of non-smokers $(p<0.05)$. More detailed data is shown in Table 5 above.

As far as the attitude towards both smoking and e-smoking in public places is concerned, medical students and students-athletes did not illustrate any difference of opinion. A disagreement between the two groups on the safety of e-smoking has not been established either. However, an insignificantly larger number of medical students (compared to students-athletes) are sure that both tobacco smoking and vaping lead to addiction $(53.6 \%$ vs $36.7 \%)(p<0.05)$.

\section{Discussion}

The percentage of the smoking population in Belarus, among residents whose age exceeds 16 years, was $24.4 \%$, which was illustrated in a random research of households carried out in Belarus at the beginning of 2015 [15]. Our research, however, indicates a decrease in prevalence of smoking by half among the surveyed students (traditional smoking was mentioned by $9.6 \%$ and $8.6 \%$ of medical students and students-athletes, respectively). The smoking of both electronic cigarettes only and a combination of electronic and tobacco cigarettes was declared by $3.4 \%$ and $1.8 \%$ of students, respectively. An attempt at smoking tobacco was confirmed by more than half of non-smoking respondents. An experience of e-smoking was referred to by approximately $38.8 \%$ of current non-smokers and $88.8 \%$ of current tobacco smokers. However, the results cannot be accurately related to the data received from the population in total, due to 
the specificity of the research group. Similar research in Poland showed that $4.4 \%$ of medical students and $12.4 \%$ of human sciences students smoked e-cigarettes [16].

Recently e-smoking has grown in popularity and is nowadays considered a healthcare issue. A European publication entitled 'Eurobarometer' revealed in 2012 that vaping among young people in Central and Eastern Europe was of rather high prevalence [2]. The frequency of e-cigarettes use in the Czech Republic was $34.3 \%$, in Bulgaria $-31.1 \%$, in Poland $-31.3 \%$, in Hungary - 31\%, in Estonia - 22.3\% and in Romania - 22.2\%, compared to the average level of $20.3 \%$ typical for the entire European Union. The data on the dynamics of e-cigarette use hints at a gradual increase of prevalence of vaping. As far as representatives of Czech and Polish youth between 2010 and 2014 are concerned, vaping consumption increased up to $9 \%$ and $30 \%$, respectively $[17,18]$. The research, carried out in 13 Eastern European cities, showed that $33 \%$ of teenagers were using e-cigarettes [19].

Interestingly, the number of dual smokers (smoking both types of cigarettes) proved to be larger than the number of exclusive e-cigarettes smokers, especially among medical students. In the aggregate, dual smokers consume a greater quantity of electronic and tobacco cigarettes compared to traditional smokers, and unlike exclusive e-smokers, they prefer e-liquid with higher levels of nicotine. Most e-smokers consider vaping safe for the health, both for themselves and others. Similar data was obtained in other research [20,21].

In some academic works, vaping is regarded as an effective method for quitting smoking $[22,23]$. A point was also made that through vaping, dual smokers reduce the number of tobacco cigarettes smoked by half [23]. In our investigation, the percentage of everyday smoking is somewhat smaller among exclusive e-smokers than among tobacco smokers. In the case of dual smoking, the number of respondents who smoke traditional cigarettes every day is $75 \%$, and this does not differ from the frequency of e-smoking (75.6\%). However, dual smokers, apart from everyday tobacco smoking, opt for everyday e-smoking (27.8\%). Overall, e-smokers consider vaping safer than traditional cigarettes, but dual smokers admit that tobacco addiction in case exclusive e-smoking vanishes insignificantly $[17,18,24,25]$. This data supports the results of a survey conducted in a group of teenagers in Poland and proves that dual smoking implies more frequent e-smoking and traditional smoking when compared to smokers of one type of cigarette [24]. This is presumably a result of stronger addiction.

As can be seen from the observations of other authors, dual smokers prefer e-liquid with higher levels of nicotine [9, 24]. Ac- cording to our records, most e-smokers prefer nicotine levels of less than $8 \mathrm{mg} / \mathrm{ml}$, and high nicotine levels $(8-16 \mathrm{mg} / \mathrm{ml}$ ) are not used. In $25.6 \%$ of cases, nicotine-free e-liquid is used. In the long run, the reduction of nicotine can be offset by an increased frequency of everyday consumption [24]. These findings contradict the formed public opinion of e-smoking being an effective method of withdrawal from tobacco smoking.

This research discovered some other factors of the transition to e-smoking. $70 \%$ of e-cigarette users declared flavor as the main factor affecting the choice of e-liquid. The flavor of tobacco was selected by only $13.5 \%$ of the respondents, and fruit or mint was chosen by $83 \%$ of e-smokers.

\section{Limitations of the study}

Taking into account the fact that the research was carried out within a specific group of students whose level of awareness of health and a healthy lifestyle is very high, the results cannot be broadly applied to all young people. The current problem of e-smoking and tobacco smoking among young people cannot be exhaustively explained without bringing in data from other cities for further comparison with this research [25]. Nonetheless, this research is characterized by a larger size sampling, and the received data substantially contributes to the epidemiological description of this newly formed problem, which is affecting both public healthcare and the health of each individual. The above-mentioned assumes that in the future, other academic centers will be affiliated with the current investigation, conducted within the international scientific project 'YoUng People E-Smoking Study' (YUPESS).

\section{Conclusions}

Vaping is neither a frequent nor popular activity among the students in both groups compared to traditional smoking. Everyday smokers prevail among dual smokers and not among exclusive e-cigarette smokers, which brings us to the assumption that vaping is used as an alternative source of nicotine, but not an alternative to tobacco smoking. E-smokers believe in the safety of vaping for both their own health and the well-being of others more than the other groups of those surveyed. Electronic smoking, as a new and increasingly popular source of nicotine, is turning into a serious challenge for public healthcare and health as such and will require further investigation of the subject matter.

Source of funding: This work was funded by the authors' own resources. Conflict of interest: The authors declare no conflict of interests.

\section{References}

1. Breland AB, Spindle T, Weaver M, et al. Science and electronic cigarettes: current data, future needs. J Addict Med 2014; 8(4): 223-233.

2. El Dib R, Suzumura EA, Akl EA, et al. Electronic nicotine delivery systems and/or electronic non-nicotine delivery systems for tobacco smoking cessation or reduction: a systematic review and meta-analysis. BMJ Open 2017; 7(2): e012680, doi: 10.1136/bmjopen-2016-012680.

3. Grana R, Benowitz N, Glantz SA. E-cigarettes: a scientific review. Circulation 2014; 129(19): 1972-1986.

4. Goniewicz ML, Zielinska-Danch W. Electronic cigarette use among teenagers and young adults in Poland. Pediatrics 2012; 130(4): 879-885.

5. Breland A, Spindle T, Weaver M, et al. Science and electronic cigarettes: current data, future needs. J Addict Med 2014; 8(4): 223-233.

6. Jankowski M, Brożek G, Lawson J, et al. E-smoking: Emerging public health problem? Int J Occup Med Environ Health 2017; 30(3): 329-344.

7. Vardavas $\mathrm{Cl}$, Filippidis FT, Agaku IT. Determinants and prevalence of e-cigarette use throughout the European Union: a secondary analysis of 26566 youth and adults from 27 Countries. Tob Control 2015; 24(5): 442-448.

8. Schraufnagel DE, Blasi F, Drummond MB, et al. Forum of International Respiratory Societies. Electronic cigarettes. A position statement of the forum of international respiratory societies. Am J Respir Crit Care Med 2014; 190(6): 611-618.

9. World Health Organization (WHO). WHO Framework Convention on Tobacco Control, Electronic nicotine delivery systems. Report by WHO (FCTC/COP/6/10). Available From URL: http://apps.who.int/gb/fctc/PDF/cop6/FCTC_COP6_10-en.pdf. 
10. Pokhrel P, Lam TH, Pagano I, et al. Young adult e-cigarette use outcome expectancies: validity of a revised scale and a short scale. Addict Behav 2017; 78: 193-199.

11. Buczkowski K, Marcinowicz L, Czachowski S, et al. Motivations toward smoking cessation, reasons for relapse, and modes of quitting: results from a qualitative study among former and current smokers. Patient Prefer Adherence 2014; 8: 1353-1363, doi: 10.2147/PPA. S67767.

12. Boratyn-Dubiel L, Binkowska-Bury M, Gugała B. Rozpowszechnienie palenia tytoniu wśród młodzieży akademickiej w Polsce. Zdr Pub/ 2008; 118(4): 474-475 (in Polish)

13. Kruk W, Hubert-Lutecka A, Zając K, et al. Palenie tytoniu przez studentów - skala problemu. Med Og Nauk Zdr 2014; 20(4): 433-438 (in Polish).

14. Brożek G, Jankowski M, Zejda J, et al. E-smoking among students of medicine - frequency, pattern and motivations. Adv Respir Med 2017; 85(1): 8-14.

15. Social conditions and living standards of population in the Republic of Belarus. Statistical book. Minsk: National Statistical Committee of the Republic of Belarus; 2015.

16. Zarobkiewicz MK, Wawryk-Gawda E, Woźniakowski MM, et al. Tobacco smokers and electronic cigarettes users among Polish universities students. Rocz Panstw Zakl Hig 2016; 67(1): 75-80.

17. Kralikova E, Novak J, West O. Do e-cigarettes have the potential to compete with conventional cigarettes?: a survey of conventional cigarette smokers' experiences with e-cigarettes. Chest 2013; 144(5): 1609-1614.

18. Goniewicz ML, Gawron M, Nadolska J. Rise in electronic cigarette use among adolescents in Poland. J Adolesc Health 2014; 55(5): 713-715.

19. Kristjansson AL, Mann MJ, Sigfusson J, et al. Prevalence of e-cigarette use among adolescents in 13 Eastern European towns and cities. Public Health 2017; 147: 66-68, doi: 10.1016/j.puhe.2017.02.005.

20. Malas M, Tempel J van der, Schwartz R, et al. Electronic cigarettes for smoking cessation: a systematic review. Nicotine Tob Res 2016; 18(10): 1926-1936.

21. Bullen Ch, Howe C, Laugesen M, et al. Electronic cigarettes for smoking cessation: a randomized controlled trial. Lancet 2013; 382(9905): 1629-1637.

22. Caponnetto P, Campagna D, Cibella F, et al. EffiCiency and Safety of an eLectronic cigAreTte (ECLAT) as tobacco cigarettes substitute: a prospective 12-month randomized control design study. PLOS ONE 2013; 8(6): e66317, doi: 10.1371/journal.pone.0066317.

23. Etter JF, Eissenberg T. Dependence levels in users of electronic cigarettes, nicotine gums and tobacco cigarettes. Drug Alcohol Depend 2015; 147: 68-75, doi: 10.1016/j.drugalcdep.2014.12.007.

24. Goniewicz ML, Leigh NJ, Gawron M, et al. Dual use of electronic and tobacco cigarettes among adolescents: a cross-sectional study in Poland. Int J Public Health 2016; 61(2): 189-197.

25. Buczkowski K, Marcinowicz L, Czachowski S, et al. „What kind of general practitioner do I need for smoking cessation?” Results from a qualitative study in Poland. BMC Fam Pract 2013; 14: 159, doi: 10.1186/1471-2296-14-159.

Tables: 5

Figures: 0

References: 25

Received: 19.12.2017

Reviewed: 23.12 .2017

Accepted: 07.01.2017

Address for correspondence:

Andrei I. Shpakou, MD, PhD, Assoc. Prof.

Department of Sports Medicine and Rehabilitation

Yanka Kupala State University of Grodno

22, Ozeshko

Grodno 230023

Belarus

Tel.: +375(29)78310343

E-mail: shpakofff@tut.by 